\title{
O uso indiscriminado e off label da Ritalina
}

\author{
The indiscriminate and off label use of Ritalin \\ El uso indiscriminado y no autorizado de Ritalin
}

Recebido: 05/08/2021 | Revisado: 10/08/2021 | Aceito: 11/08/2021 | Publicado: 15/08/2021

Natasha Costa da Rocha Galucio

ORCID: https://orcid.org/0000-0003-4923-1478

Escola Superior da Amazônia, Brasil

E-mail: natashagalucio@gmail.com

Regianne Maciel dos Santos Correa

ORCID: https://orcid.org/0000-0002-9837-4304

Escola Superior da Amazônia, Brasil

E-mail: regianne83@hotmail.com

Vanessa Barbosa Ferreira

ORCID: https://orcid.org/0000-0003-4892-6999

Escola Superior da Amazônia, Brasil

E-mail: vanessa-kimble@hotmail.com

Erissâmia do Socorro da Silva Fonteles

ORCID: https://orcid.org/0000-0002-4261-3943

Escola Superior da Amazônia, Brasil

E-mail: erissamiafonteles@gmail.com

Deusilene Braga Barbosa

ORCID: https://orcid.org/0000-0001-8977-6080

Escola Superior da Amazônia, Brasil

E-mail: lennebraga725@gmail.com

Daniele de Araújo Moysés

ORCID: https://orcid.org/0000-0001-6956-1381

Universidade Federal do Pará, Brasil

E-mail: quimica.dani@gmail.com

Gleicy Kelly China Quemel

ORCID: https://orcid.org/0000-0003-1280-560X Escola Superior da Amazônia, Brasil

E-mail: gkcquemel@gmail.com

Valdicley Vieira Vale

ORCID: https://orcid.org/0000-0001-6570-4875

Escola Superior da Amazônia, Brasil

E-mail: valdicleyvale@gmail.com

\begin{abstract}
Resumo
O cloridato de metilfenidato [(dl-treo-metil-2-fenil-2- (2-piperidil) acetato], conhecido como Ritalina é um psicofármaco usado geralmente por pessoas com Transtorno de Déficit de Atenção e Hiperatividade (TDAH) e com narcolepsia, para o seu tratamento. Por se tratar de um medicamento que age no sistema nervoso liberando noradrenalina e dopamina nas fendas sinápticas, incidindo uma excitação nos receptores pós-sinápticos e altera as funções cognitivas do usuário, o uso off label para melhorar o desempenho cognitivo está sendo cada vez mais comum. Este tipo de medicamento deve ser usado de forma racional, bem como qualquer outra medicação, pois podem causar efeitos adversos e dependência. Em vista do exposto, este estudo objetivou avaliar, por meio da literatura, a forma correta de uso do metilfenidato, o uso indiscriminado, off label e os problemas de saúde que o uso prolongado pode desencadear no usuário, assim como a importância da atenção farmacêutica para um tratamento eficaz com metilfenidato. Para isso, foi realizada uma revisão integrativa da literatura e os artigos para esta revisão foram coletados nos seguintes portais de pesquisa: SciELO, BVS e Lilacs. Após a coleta, foram selecionados 21 estudos para compor os resultados. Foi possível perceber que o uso indiscriminado do cloridrato de metilfenidato tem sido realizado com frequência por muitas pessoas, principalmente por estudantes, podendo levar a complicações sérias e o aparecimento de efeitos adversos graves, principalmente eventos cardiovasculares como taquicardia e hipertensão, transtornos psiquiátricos como depressão, psicose e dependência química, bem como do sistema neurológico como discinesia, contrações musculares involuntárias e espasmos, entre outros.
\end{abstract}

Palavras-chave: Off label; Uso racional; Ritalina; Metilfenidato.

\footnotetext{
Abstract

Methylphenidate hydrochloride [(dl-treo-metil-2-fenil-2- (2-piperidil) acetato], known as Ritalin, is a psychotropic drug commonly used by people with Attention Deficit Hyperactivity Disorder (ADHD) and narcolepsy for its
} 
treatment. As it is a drug that acts on the nervous system by releasing norepinephrine and dopamine in the synaptic clefts, causing an excitation in postsynaptic receptors and altering the user's cognitive functions, the off label use to improve cognitive performance is becoming more and more common. This type of medication must be used rationally, as well as any other medication, as they can cause adverse effects and dependence. In view of the above, this study aimed to evaluate, through the literature, the correct way to use methylphenidate, the indiscriminate use, off label and the health problems that prolonged use can trigger in the user, as well as the importance of pharmaceutical care for effective treatment with methylphenidate. For this, an integrative literature review was carried out and the articles for this review were collected in the following search portals: SciELO, BVS and Lilacs. After collection, 21 studies were selected to compose the results. It was possible to notice that the indiscriminate use of methylphenidate hydrochloride has been carried out frequently by many people, especially by students, which can lead to serious complications and the appearance of serious adverse effects, especially cardiovascular events such as tachycardia and hypertension, psychiatric disorders such as depression, psychosis and chemical dependency, as well as the neurological system such as dyskinesia, involuntary muscle contractions and spasms, among others.

Keywords: Off label; Rational use; Ritalin; Methylphenidate.

\section{Resumen}

El clorhidrato de metilfenidato [(dl-treo-metil-2-fenil-2- (2-piperidil) acetato], conocido como Ritalin, es un fármaco psicotrópico comúnmente utilizado por personas con trastorno por déficit de atención con hiperactividad (TDAH) y narcolepsia para su tratamiento. Al ser un fármaco que actúa sobre el sistema nervioso liberando noradrenalina y dopamina en las hendiduras sinápticas, provocando una excitación en los receptores postsinápticos y alterando las funciones cognitivas del usuario, el uso off label para mejorar el rendimiento cognitivo es cada vez más común. Este tipo de medicación debe utilizarse de forma racional, así como cualquier otra medicación, ya que pueden provocar efectos adversos y dependencia. En vista de lo anterior, este estudio tuvo como objetivo evaluar, a través de la literatura, la forma correcta de usar metilfenidato, el uso indiscriminado, off label y los problemas de salud que el uso prolongado puede desencadenar en el usuario, así como la importancia de la atención farmacéutica. para un tratamiento eficaz con metilfenidato. Para ello, se realizó una revisión integradora de la literatura y los artículos para esta revisión se recolectaron en los siguientes portales de búsqueda: SciELO, BVS y Lilacs. Después de la recopilación, se seleccionaron 21 estudios para componer los resultados. Se pudo notar que el uso indiscriminado de clorhidrato de metilfenidato ha sido realizado con frecuencia por muchas personas, especialmente por estudiantes, lo que puede derivar en complicaciones graves y la aparición de efectos adversos graves, especialmente eventos cardiovasculares como taquicardia e hipertensión, trastornos psiquiátricos. como depresión, psicosis y dependencia química, así como del sistema neurológico como discinesia, contracciones musculares involuntarias y espasmos, entre otros.

Palabras clave: Off label; Uso racional; Ritalin; Metilfenidato.

\section{Introdução}

O cloridrato de metilfenidato [(dl-treo-metil-2-fenil-2- (2-piperidil) acetato] é um estimulante do sistema nervoso central (SNC) derivado da piperidina que é estruturalmente semelhante à anfetamina e atua como uma norepinefrina - inibidor da recaptação da dopamina. Aumenta a neurotransmissão dopaminérgica, particularmente nos níveis estriatal e frontal, ao inibir os transportadores de dopamina pré-sináptica (Eslami et al., 2014). Ao bloquear a recaptação de noradrenalina e dopamina no nível do neurônio pré-sináptico, o metilfenidato, aumenta a liberação dessas monoaminas no nível da fenda sináptica. O resultado da ação desse fármaco final é maior atenção, função motora e memória. No Brasil, o cloridrato de metilfenidato é comercializado como Ritalina (Ortega et al., 2010). A legislação brasileira restringe a prescrição e dispensação de entorpecentes ou substâncias psicotrópicas. As prescrições exigem documentação antes da dispensação. O formulário de notificação de prescrição é utilizado para autorizar a comercialização de substâncias em listas específicas de medicamentos sujeitos a controle especial: Lista A (amarela), para entorpecentes e psicotrópicos mais restritos, seguida das Listas B (azul) e C (Branco). As notificações em amarelo e azul são retidas pelas farmácias no momento da compra (ANVISA, 1998). O formulário de notificação de prescrição para metilfenidato pertence à Lista $\mathrm{A}$, e tem um tratamento máximo recomendado de 30 dias, consistente para esta classe de substância. Além disso, as listas de balanço de medicamentos - psicoativos e outros sujeitos a controle especial são utilizadas para registrar todas as compras e vendas controladas pelas informações da vigilância municipal, incluindo a farmácia, o farmacêutico responsável e os medicamentos prescritos e dispensados. Cada farmácia é obrigada a enviar periodicamente essas informações às autoridades de vigilância sanitária local e o processo tem sido 
controlado por um sistema de registro online por meio do serviço de vigilância nacional desde 2007 (Masini, Dantas \& Nunes, 2019). Além disso, a dispensação de medicamentos controlados, conta com o registro de cada medicamento no Sistema Nacional de Gerenciamento de Produtos Controlados (SNGPC). Esse sistema é um conjunto de instrumentos informatizados utilizado para realizar o monitoramento de movimentação de medicamentos e substancias sujeitos a controle especial. Além de utilizado em farmácias e drogarias 14 particulares, que trabalham com medicamentos controlados, o SNGPC é implementado também em farmácias hospitalares, publicas, distribuidoras e indústrias de insumos e medicamentos controlados (ANVISA, 2007) O metilfenidato (Ritalina) é indicado para o tratamento do Transtorno de Déficit de Atenção e Hiperatividade (TDAH), um dos transtornos psiquiátricos mais comuns diagnosticados em crianças, além disso, pode ser indicado para adultos com narcolepsia. Porém, o uso indevido desse medicamento aumentou drasticamente nos últimos anos com base em conceitos errados sobre o produto ou pela simples falta de conhecimento dos riscos associados (Winterstein et al., 2012). Ressalta-se que apesar das indicações limitadas e das condições rigorosas de sua prescrição e dispensação, existe o uso off label de metilfenidato. De acordo com o art. $3^{\circ}$ da Resolução Normativa, $n^{\circ} 424$ de junho de 2017, a ANVISA, determina que o medicamento em uso off label são aqueles usados intencionalmente para uma finalidade médica, que não está de acordo com a informação do produto autorizada do registro efetuado pela Anvisa. Por todo o exposto, faz-se necessário realizar uma revisão bibliográfica que comprove a real situação do uso do metilfenidato, seus efeitos colaterais e efeitos adversos, uso abusivo desse medicamento e suas consequências. Nesse sentido, o presente estudo avaliou, por meio da literatura, a forma correta de uso do metilfenidato, o uso indiscriminado, off label e os problemas de saúde que o uso prolongado pode desencadear no usuário, assim como a importância da atenção farmacêutica para um tratamento eficaz com metilfenidato (ANVISA, 2017).

\section{Metodologia}

\subsection{Tipo de Estudo, Bancos de Dados e Descritores Utilizados}

Para alcançar os objetivos apresentados neste estudo, foi realizada uma pesquisa bibliográfica de revisão integrativa, que visa interpretar e compreender determinada questão se alicerçando em evidencias já disponíveis na literatura (Galvão, Sawada, \& Mendes, 2003). De acordo com Ganong (1987), a revisão integrativa deve ser elaborada em 6 etapas. As etapas determinadas neste estudo estão apresentadas na Figura 1.

Figura 1: Descrição das seis fases realizadas para a elaboração da revisão integrativa.

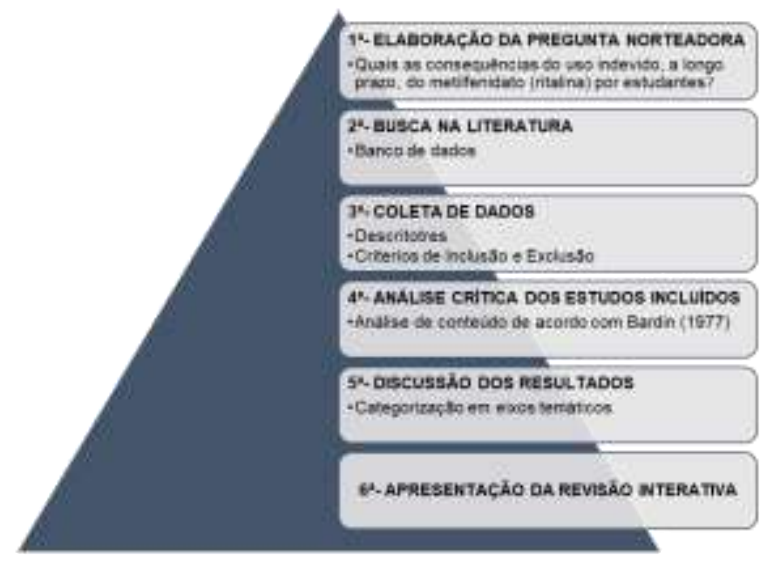

Fonte: Autores.

A fim de entender as consequências do uso indevido de Ritalina, a pesquisa foi realizada nos seguintes bancos de 
dados Biblioteca Virtual de Saúde (BVS), Publicattions of Medical Literature Analysisand Retrievel System Online (PubMed) e Scientific Electronic Library Online (SciELO). No campo da busca de dados foram utilizados os seguintes Descritores em Ciências da Saúde (DeCS): "metilfenidato/ Methylphenidate"; "automedicação/self medication"; "estudantes/ students" e "uso off labell off label use". Para refinar as buscas foi utilizado o seguinte esquema dos operadores booleanos (quadro 1). Assim, foram considerados todos os estudos que pudessem conter esses grupos de palavras.

Quadro 1: Organização do termo de busca com o operador booleano.

\begin{tabular}{|c|c|c|c|c|c|}
\hline DESCRITOR & TERMO-CHAVE & OPERAR & TERMO-CHAVE & OPERAR & TERMO-CHAVE \\
\hline $\mathbf{1}$ & $\begin{array}{c}\text { "metilfenidato/ } \\
\text { Methylphenidate" }\end{array}$ & AND & "uso off label/ off label use" & AND & "estudantes/ students" \\
\hline $\mathbf{2}$ & $\begin{array}{c}\text { "metilfenidato/ } \\
\text { Methylphenidate" }\end{array}$ & AND & $\begin{array}{c}\text { "automedicação/ self } \\
\text { medication" }\end{array}$ & AND & "estudantes/ students \\
\hline
\end{tabular}

Fonte: Autores.

\subsection{Critérios de Inclusão e Exclusão}

Para constituir a amostra, foram selecionados os trabalhos que atenderam aos seguintes critérios de inclusão: documentos apresentados a partir dos descritores; publicados nos últimos dez anos (2011-2021); disponível nos idiomas português e inglês e que versavam sobre a temática em enfoque. Os critérios de exclusão foram artigos não disponíveis na íntegra, duplicados e de acesso restrito

\subsection{Análise de Dados}

Foi realizada a análise de conteúdo segundo Bardin (1977). Operacionalmente, essa é uma técnica de análise das comunicações que utiliza procedimentos sistemáticos e objetivos de descrição do conteúdo das mensagens. Desse modo, os estudos analisados foram segregados em eixos temáticos visando responder aos objetivos propostos neste estudo. A autora determina, ainda, três diferentes fases de organização da análise que, neste estudo, foram construídas de acordo com a figura 2.

Figura 2: As três fases de construção da Análise de Conteúdo.

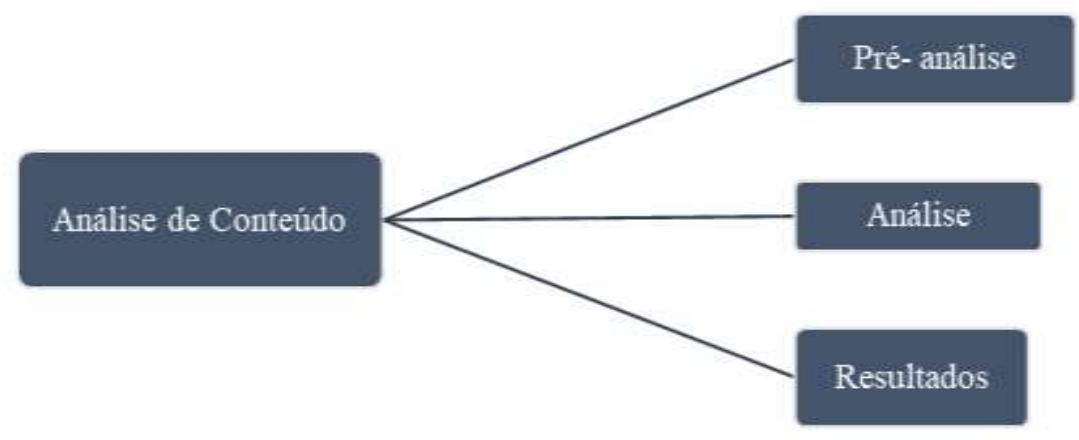

Fonte: Adaptado de Bardin (1977).

\subsection{Pré- análise}

Na primeira etapa, estabelecida pela autora, foi realizada a coleta dos estudos utilizando as condições apresentadas nos tópicos 2.1 e 2.2. Nesta fase foi possível realizar: 
- Uma leitura flutuante do material;

- Escolher os documentos que serão analisados;

- Preparar o material.

Para selecionar os estudos na segunda fase da análise de conteúdo, foram utilizados cinco filtros, em conformidade com os critérios de inclusão e exclusão. No universo de 563 estudos existentes nos bancos de dados, 30 foram selecionados para a segunda fase da Análise de Conteúdo. O Quadro 2 demonstra essa seleção.

Quadro 1: Documentos selecionados na pré-análise. DESC. 1 (Descritor 1) = "metilfenidato/ Methylphenidate [AND] "uso off labell off label use" [AND] "estudantes/ students". DESC. 2 (Descritor 2) = "metilfenidato/Methylphenidate [AND] automedicação/ self medication [AND] estudantes/ students".

\begin{tabular}{|c|c|c|c|c|c|c|c|}
\hline \multirow{2}{*}{ FILTRo } & \multicolumn{2}{|c|}{ BVS } & \multicolumn{2}{c|}{ PubMed } & \multicolumn{2}{c|}{ SciELO } & \multirow{2}{*}{ PRÉ-ANÁLISE } \\
\cline { 2 - 7 } & Desc.1 & Desc.2 & Desc.1 & Desc.2 & Desc.1 & Desc.2 & \multirow{2}{*}{} \\
\cline { 2 - 8 } & 86 & 101 & 189 & 137 & 15 & 35 & \\
\hline Período & 38 & 79 & 57 & 85 & 5 & 21 & \\
\hline Completo & 34 & 69 & 57 & 85 & 5 & 21 & \\
\hline Idiomas & 28 & 26 & 57 & 85 & 5 & 18 & \multirow{3}{*}{} \\
\hline Acesso livre & 10 & 12 & 6 & 8 & 1 & 1 & 1 \\
\hline Não duplicados & 8 & 10 & 2 & 8 & 1 & & \\
\hline
\end{tabular}

Fonte: Autores.

Durante as buscar, notou-se uma elevada quantidade de estudos relacionados aos descritores "metilfenidato/ Methylphenidate [AND] automedicação/ self medication [AND] estudantes/ students". Ressalta-se, ainda, que a PubMed foi o banco de dados com maior número de publicações em sua plataforma sobre esse assunto e os filtros "período" e "acesso livre" foram aos que mais excluíram estudos.

\subsection{Análise}

Dentro desta fase, foi realizada a codificação e categorização do material. Na codificação, foi possível selecionar, entre os 30 artigos, os que condiziam com os objetivos deste estudo. O fluxograma a seguir (Figura 3) expressa de maneira ampla a exclusão e seleção do material, com ênfase na quantidade de estudos que não contemplaram os objetivos. 
Figura 3: Fluxograma de seleção dos artigos para o estudo, com base nos critérios de inclusão e exclusão.

563

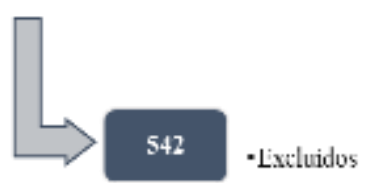

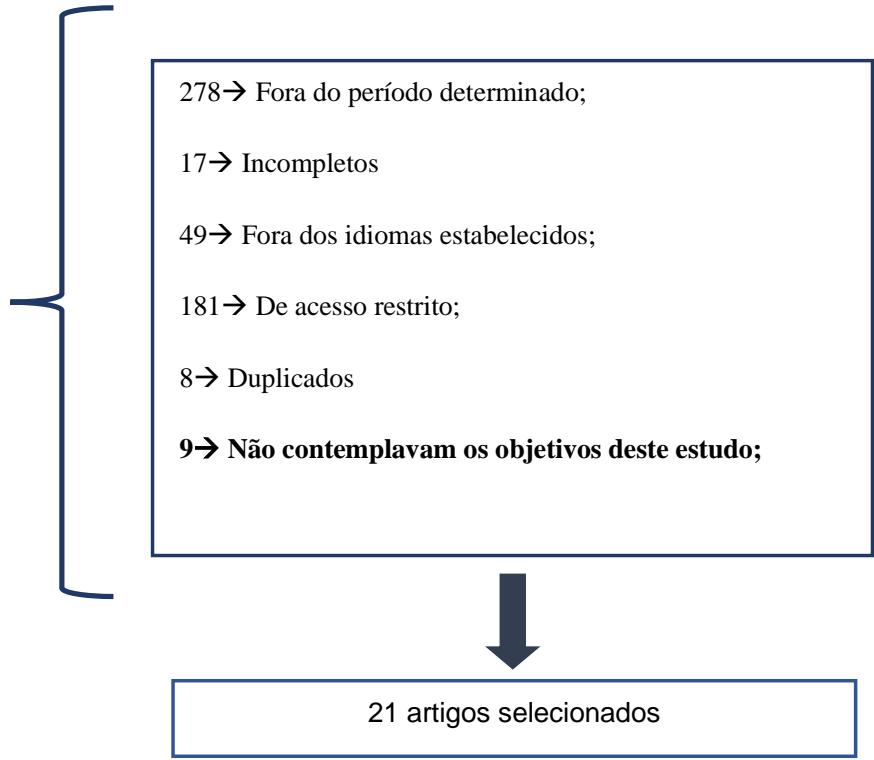

Fonte: Autores.

Após a codificação foi realizada a categorização e para isso, os 21 estudos selecionados foram separados em unidades de registro. Essas unidades descrevem o assunto abordado pelos estudos. Por fim, com base nesses assuntos, foram formuladas categorias de analise ou eixos temáticos, que se relacionam aos objetivos propostos neste estudo (Quadro 3).

Quadro 2: Categorização em eixos temáticos.

\begin{tabular}{|l|l|}
\hline UNIDADE DE REGISTRO & EIXOS TEMÁTICOS \\
\cline { 1 - 2 } Uso de metilfenidato por universitários. & $\begin{array}{l}\text { Indicações terapêuticas do medicamento metilfenidato e as } \\
\text { consequências do uso prolongado. }\end{array}$ \\
\cline { 1 - 1 } Consequências do uso de metilfenidato. & $\begin{array}{l}\text { Evidências do uso do metilfenidato sem indicação. terapêutica, } \\
\text { por estudantes, motivos e consequências. }\end{array}$ \\
\cline { 1 - 2 } Automedicação com metilfenidato. & $\begin{array}{l}\text { Impacto da atenção farmacêutica no uso racional de } \\
\text { Curso da área da saúde o uso de metilfenidato. }\end{array}$ \\
\cline { 1 - 2 } Dispensação de metilfenidato.
\end{tabular}

Fonte: Autores.

\subsection{Tratamento e Interpretação dos Resultados}

A interpretação dos resultados obtidos foi realizada por meio da interpretação de inferência. Segundo Bardin (1977), esse mecanismo é um tipo de interpretação controlada que permite ao analista apoiar-se nos elementos apresentados nos estudos selecionados. Neste estudo, essa interpretação consistiu nos seguintes passos:

- Apresentação dos estudos selecionados

- Explanação dos eixos temáticos

\section{Resultados e Discussão}

\subsection{Apresentação dos estudos selecionados}

Como já mencionado, após a análise dos 30 estudos restantes, 21 foram eleitos para compor estes resultas. O quadro 4 organiza os estudos em cronologia, evidenciando o autor/ano de publicação, o banco de dado de origem, a metodologia do estudo, os objetivos e seus resultados. 
Research, Society and Development, v. 10, n. 10, e443101019108, 2021

(CC BY 4.0) | ISSN 2525-3409 | DOI: http://dx.doi.org/10.33448/rsd-v10i10.19108

Quadro 3: Estudos selecionados para a revisão.

\begin{tabular}{|c|c|c|c|c|c|}
\hline $\mathbf{N}^{\circ}$ & $\begin{array}{l}\text { AUTOR/ } \\
\text { ANO }\end{array}$ & $\begin{array}{l}\text { BANCO DE } \\
\text { DADO }\end{array}$ & OBJETIVO & METODOLOGIA & RESULTADOS \\
\hline 1 & $\begin{array}{l}\text { (Girotto, Costa, \& } \\
\text { Borges, 2011) }\end{array}$ & SicELO & $\begin{array}{l}\text { Caracterizar as notificações } \\
\text { de receitas (NR), com } \\
\text { prescrição de metilfenidato, } \\
\text { em três lojas de uma rede de } \\
\text { farmácias do município de } \\
\text { Londrina, Paraná. } \\
\end{array}$ & $\begin{array}{l}\text { A amostra caracterizada foi composta por } 335 \\
\text { notificações de receitas retidas pelos } \\
\text { estabelecimentos entre os meses de janeiro e } \\
\text { julho do ano de } 2010 .\end{array}$ & $\begin{array}{l}\text { Dentre as três apresentações disponíveis no mercado, o } \\
\text { medicamento Ritalina }{ }^{\circledR} \text { foi o mais prevalente, aparecendo em } \\
82,7 \% \text { das NR, assim como os pacientes do sexo masculino } \\
(76,7 \%) \text { e as NR provenientes do setor privado }(82,7 \%) \text {. }\end{array}$ \\
\hline 2 & $\begin{array}{c}\text { (Burgard et al., } \\
\text { 2013) }\end{array}$ & SciELO & $\begin{array}{l}\text { Apresentar tendências no uso } \\
\text { drogas para TDH em um } \\
\text { campus universitário entre } \\
\text { períodos de baixo e alto } \\
\text { estresse. }\end{array}$ & $\begin{array}{l}\text { Os metabólitos dessas duas drogas, } \\
\text { anfetamina e ácido ritalínico, foram } \\
\text { quantificados em águas residuais do campus } \\
\text { usando extração de fase sólida (SPE) e } \\
\text { cromatografia líquida-espectrometria de } \\
\text { massa em tandem (LC-MS / MS). }\end{array}$ & $\begin{array}{c}\text { Os níveis de ácido ritalínico aumentaram radualmente no primeiro } \\
\text { semestre, mas não tiveram tendência periódica óbvia no segundo } \\
\text { semestre. }\end{array}$ \\
\hline 3 & $\begin{array}{c}\text { (Eslami et al., } \\
\text { 2014) }\end{array}$ & BVS & $\begin{array}{l}\text { Comparar duas construções } \\
\text { congnitvas (intenção } \\
\text { comportamental ou } \\
\text { disposição comportamental) } \\
\text { para prever o uso indevido de } \\
\text { Ritalina }\end{array}$ & $\begin{array}{c}\text { Estudo transversal conduzido entre } 264 \\
\text { estudantes universitários de medicina } \\
\text { iranianos; participantes selecionados em } \\
\text { amostragem aleatória, e os dados foram } \\
\text { coletados por meio de questionário de } \\
\text { autorrelato. }\end{array}$ & $\begin{array}{l}10 \% \text { dos entrevistados afirmou fazer uso de Ritalina sem } \\
\text { prescrição. Desses, } 21 \% \text { eram tabagistas e } 15 \% \text { consumia álcool } \\
\text { mesmo no período em que fazia uso da droga. } 70 \% \text { dos que } \\
\text { usavam, afirmaram que pretendiam obter melhorias no } \\
\text { desempenho acadêmico. }\end{array}$ \\
\hline 4 & $\begin{array}{c}\text { (Silveira et al., } \\
\text { 2014) }\end{array}$ & PubMed & $\begin{array}{l}\text { Avaliar a prevalência do uso } \\
\text { do metilfenidato entre } \\
\text { estudantes do } 5^{\circ} \text { e do } 6^{\circ} \text { ano } \\
\text { de uma faculdade de } \\
\text { medicina, discriminar o uso } \\
\text { com ou sem indicação médica } \\
\text { e correlacionar o uso de } \\
\text { metilfenidato com a ingestão } \\
\text { de álcool. }\end{array}$ & $\begin{array}{l}\text { Estudo transversal, em que os alunos de } \\
\text { medicina foram convidados a responder um } \\
\text { questionário para avaliação do status } \\
\text { socioeconômico e acadêmico, padrões do uso } \\
\text { do metilfenidato e atitude em relação a drogas } \\
\text { potencializadoras da cognição. Também foi } \\
\text { aplicado o questionário The Alcohol Use } \\
\text { Disorder Identification Test (AUDIT), que } \\
\text { avalia o consumo de bebidas alcoólicas, onde } \\
\text { um score } \geq 8 \text { significa ingestão } \\
\text { potencialmente } \\
\text { perigosa de álcool. }\end{array}$ & $\begin{array}{l}52 \text { participantes }(34,2 \%) \text { já haviam usado metilfenidato, sendo que } \\
35 \text { destes }(23,02 \%) \text { haviam usado a substância sem indicação } \\
\text { médica. O número de estudantes do } 6^{\circ} \text { ano que fizeram uso não } \\
\text { médico de metilfenidato foi mais de duas vezes maior do que o } \\
\text { número de estudantes do } 5^{\circ} \text { ano }(32,89 \text { versus } 13,15 \% \text {, } \\
\text { respectivamente; } \mathrm{p}=0,004) \text {. Em relação ao AUDIT, } 43,6 \% \text { ( } \mathrm{p}= \\
0,031) \text { dos usuários de metilfenidato tiveram escores } \geq 8 ; 33,3 \% \text { ( } \mathrm{p} \\
=0,029) \text { dos usuários não médicos de metilfenidato tiveram } \\
\text { escores } \geq 8 \text { no AUDIT. }\end{array}$ \\
\hline 5 & $\begin{array}{l}\text { (Cohen et al., } \\
\text { 2015) }\end{array}$ & BVS & $\begin{array}{l}\text { Avaliar o uso médico e não } \\
\text { médico de metilfenidato entre }\end{array}$ & $\begin{array}{l}\text { Os estudantes de medicina foram solicitados } \\
\text { a relatar o uso de metilfenidato, sintomas e }\end{array}$ & $\begin{array}{l}\text { Participaram do estudo } 229 \text { alunos, dos quais } 105(45,9 \%) \text { estavam } \\
\text { nos anos pré - clínicos do curso de medicina. Vinte e dois alunos }\end{array}$ \\
\hline
\end{tabular}


Research, Society and Development, v. 10, n. 10, e443101019108, 2021

(CC BY 4.0) | ISSN 2525-3409 | DOI: http://dx.doi.org/10.33448/rsd-v10i10.19108

\begin{tabular}{|c|c|c|c|c|c|}
\hline $\mathbf{N}^{\mathbf{o}}$ & $\begin{array}{l}\text { AUTOR/ } \\
\text { ANO }\end{array}$ & $\begin{array}{l}\text { BANCO DE } \\
\text { DADO }\end{array}$ & OBJETIVO & METODOLOGIA & RESULTADOS \\
\hline & & & $\begin{array}{l}\text { estudantes de medicina na } \\
\text { Universidade Ben-Gurion de } \\
\text { Negev. }\end{array}$ & $\begin{array}{l}\text { diagnóstico de transtorno de déficit de } \\
\text { atenção por meio de um questionário } \\
\text { estruturado. }\end{array}$ & $\begin{array}{l}\text { (9,6\%) foram previamente diagnosticados com transtorno de déficit } \\
\text { de atenção. Uso vitalício de metilfenidato foi relatado por } 39 \\
(17 \%) \text { alunos, enquanto } 31 \text { alunos }(13,5 \%) \text { relataram o uso de } \\
\text { metilfenidato durante os } 12 \text { meses anteriores. No início da } \\
\text { faculdade de medicina, apenas } 7 \% \text { dos alunos usavam } \\
\text { metilfenidato, a maioria deles começou a usá-lo durante os anos } \\
\text { letivos pré-clínicos. } \\
\end{array}$ \\
\hline 6 & $\begin{array}{l}\text { (Morgan et al., } \\
\text { 2017) }\end{array}$ & BVS & $\begin{array}{l}\text { Investigar o uso de } \\
\text { substâncias estimulantes do } \\
\text { sistema nervoso central pelos } \\
\text { estudantes de graduação em } \\
\text { Medicina da Universidade } \\
\text { Federal do Rio Grande - Furg } \\
\text { (RS). }\end{array}$ & $\begin{array}{c}\text { Foi realizado um estudo quantitativo } \\
\text { observacional do tipo transversal com } 200 \\
\text { estudantes de graduação } \\
\text { em Medicina da Furg, matriculados nessa } \\
\text { instituição no segundo semestre de 2015. Para } \\
\text { a coleta de } \\
\text { dados, utilizou-se um questionário } \\
\text { padronizado e de autopreenchimento, com } \\
\text { questões demográficas, comportamentais e } \\
\text { sobre o uso de estimulantes. }\end{array}$ & $\begin{array}{l}\text { A prevalência de consumo de metilfenidato }\left(\text { Ritalina }{ }^{\circledR}\right) \\
\text { durante a vida foi de } 20 \%(\mathrm{n}=40) \text { e no momento da pesquisa de } \\
5,5 \%(\mathrm{n}=11) \text {, sendo que, entre os últimos, } 64 \%(\mathrm{n}=7) \text { iniciaram o } \\
\text { consumo durante o curso de Medicina. }\end{array}$ \\
\hline 7 & $\begin{array}{l}\text { (Roedel, } \\
\text { Margarina \& } \\
\text { Paim 2017) }\end{array}$ & BVS & $\begin{array}{l}\text { Compreender o uso de } \\
\text { metilfenidato entre estudantes } \\
\text { de Psicologia de uma } \\
\text { instituição de ensino superior } \\
\text { da Serra Gaúcha. }\end{array}$ & $\begin{array}{l}\text { Trata-se de um estudo transversal, descritivo } \\
\text { e com abordagem quantitativa. Foi aplicado } \\
\text { um questionário contendo questões fechadas } \\
\text { aos estudantes. Os dados foram organizados } \\
\text { em tabelas e gráficos com frequências } \\
\text { absolutas e percentuais e analisados através } \\
\text { de estatística descritiva. }\end{array}$ & $\begin{array}{l}71,6 \% \text { dos entrevistados eram do sexo feminino, a faixa etária } \\
\text { prevalente ficou entre } 18-25 \text { anos. Quanto ao semestre curricular } \\
\text { no curso de Psicologia, a maior parte encontrava-se no } 9^{\circ} \text { semestre. } \\
\text { No que se refere ao conhecimento do metilfenidato e seu } \\
\text { mecanismo de ação, } 100 \% \text { dos entrevistados afirmaram conhecer o } \\
\text { fármaco, porém destes, apenas } 24 \% \text { afirmaram não conhecer seu } \\
\text { mecanismo de ação. Em relação ao uso da substância entre os } \\
\text { acadêmicos entrevistados, a prevalência de respostas 'Não' foi de } \\
94,2 \% \text {. }\end{array}$ \\
\hline 8 & (Moura, 2017) & BVS & $\begin{array}{l}\text { Descrever os riscos que o uso } \\
\text { prolongado e não terapêutico } \\
\text { de Metilfenidato pode causar } \\
\text { à saúde. }\end{array}$ & $\begin{array}{l}\text { Revisão de literatura pesquisada em bases de } \\
\text { dados como } S c i E L O \text { e Google Acadêmico, } \\
\text { através de revistas eletrônicas e monografias } \\
\text { entre o ano de } 1990 \text { a } 2017 \text {. }\end{array}$ & $\begin{array}{l}\text { Pôde-se observar que ao longo dos anos houve um crescimento } \\
\text { mundialmente expressivo do consumo de Metilfenidato. Essa } \\
\text { elevação abrupta do consumo se deve principalmente ao fato de } \\
\text { que muitas pessoas fazem o uso do mesmo com finalidades não } \\
\text { terapêuticas, como por exemplo, aumentar seus rendimentos nos } \\
\text { estudos e trabalhos. }\end{array}$ \\
\hline 9 & & & Caracterizar o perfil do uso de & Trata-se de um estudo transversal e & $\begin{array}{l}\text { Com relação ao uso de metilfenidato } 18 \% \text { afirmaram já tê-lo } \\
\text { praticado, sendo que desses } 45 \% \text { o adquiriram com receita médica. }\end{array}$ \\
\hline
\end{tabular}


Research, Society and Development, v. 10, n. 10, e443101019108, 2021

(CC BY 4.0) | ISSN 2525-3409 | DOI: http://dx.doi.org/10.33448/rsd-v10i10.19108

\begin{tabular}{|c|c|c|c|c|c|}
\hline $\mathbf{N}^{\circ}$ & $\begin{array}{l}\text { AUTOR/ } \\
\text { ANO }\end{array}$ & $\begin{array}{c}\text { BANCO DE } \\
\text { DADO }\end{array}$ & OBJETIVO & METODOLOGIA & RESULTADOS \\
\hline & $\begin{array}{c}\text { (Alberto et al., } \\
\text { 2017) }\end{array}$ & BVS & $\begin{array}{l}\text { metilfenidato entre } \\
\text { acadêmicos de um centro } \\
\text { universitário localizado no } \\
\text { interior do estado de } \\
\text { Rondônia. }\end{array}$ & $\begin{array}{c}\text { exploratório, desenvolvido junto ao Centro } \\
\text { Universitário Luterano de Ji-Paraná } \\
\text { (CEULJ/ULBRA) } \\
\text { A população foi constituída por } \\
\text { acadêmicos da área da saúde que possuíam } \\
\text { disciplinas relacionadas à farmacologia na } \\
\text { grade, o que incluiu os cursos de } \\
\text { Biomedicina, Enfermagem e Farmácia. }\end{array}$ & $\begin{array}{c}\text { O principal motivo de uso foi para melhoria do aprendizado (85\%), } \\
\text { onde a maioria dos acadêmicos afirmou terem alcançado o efeito } \\
\text { desejado, apesar de } 59 \% \text { relataram efeitos adversos. }\end{array}$ \\
\hline 10 & $\begin{array}{c}\text { (Roshini et al., } \\
\text { 2017) }\end{array}$ & SicELO & $\begin{array}{l}\text { Investigar a prevalência do } \\
\text { uso não medicinal do } \\
\text { metilfenidato e o } \\
\text { conhecimento dessa droga } \\
\text { entre estudantes de graduação } \\
\text { em Medicina da Universidade } \\
\text { do Estado Livre }\end{array}$ & $\begin{array}{l}\text { Estudo transversal. Um questionário } \\
\text { autoaplicável e anônimo foi } \\
\text { distribuído durante as palestras a } \\
\text { todos os alunos das turmas de cinco } \\
\text { anos do curso de graduação em } \\
\text { medicina. }\end{array}$ & $\begin{array}{c}\text { Dos } 643 \text { alunos de graduação em medicina, } 541 \\
\text { responderam ao questionário (taxa de resposta: } \\
84,1 \% \text { ). Aproximadamente } 11,0 \% \text { dos alunos } \\
\text { pesquisados faziam uso de metilfenidato no } \\
\text { momento do estudo, sendo que a maioria }(67,9 \%) \\
\text { utilizava para fins acadêmicos e } 70,6 \% \text { o recebia } \\
\text { de um profissional de saúde. Menos de um terço } \\
\text { dos usuários foram diagnosticados com } \\
\text { Transtorno de Déficit de Atenção / Hiperatividade. } \\
\text { O conhecimento médio dos usuários de } \\
\text { metilfenidato foi maior do que os não usuários, e } \\
\text { o conhecimento de metilfenidato aumentou dos } \\
\text { alunos do primeiro e segundo ano para os alunos } \\
\text { do terceiro e quinto ano. }\end{array}$ \\
\hline 11 & $\begin{array}{l}\text { (Abbasi- } \\
\text { Ghahramanloo et } \\
\text { al., 2018) }\end{array}$ & PubMed & $\begin{array}{l}\text { Determinar a prevalência do } \\
\text { uso de opioides prescritos, } \\
\text { metilfenidato e sedativos- } \\
\text { hipnóticos, e fatores } \\
\text { relacionados em estudantes } \\
\quad \text { universitários. }\end{array}$ & $\begin{array}{l}\text { Estudo transversal, } 524 \text { estudantes da } \\
\text { Hormozgan University of Medical Sciences } \\
\text { foram selecionados por amostragem em } \\
\text { múltiplos estágios em } 2016 .\end{array}$ & $\begin{array}{l}\text { A prevalência de uso de opioides prescritos, metilfenidato e } \\
\text { sedativos-hipnóticos no último ano foi de } 16,1 \%, 3,3 \% \text { e } 10,3 \% \text {, } \\
\text { respectivamente. O modelo final de regressão logística indicou o } \\
\text { uso de narguilé }(\mathrm{OR}=2,5) \text {, uso de metilfenidato }(\mathrm{OR}=4,5) \text {, uso de } \\
\text { sedativos-hipnóticos }(\mathrm{OR}=2,7) \text { e foram associados ao uso de } \\
\text { opioides do tipo prescrito pelos alunos. }\end{array}$ \\
\hline 12 & (Deganutti, 2019) & PubMed & $\begin{array}{l}\text { Apontar os motivos que } \\
\text { levam estudantes saudáveis a } \\
\text { fazerem uso do MTF. }\end{array}$ & $\begin{array}{l}\text { Revisão de literatura, no qual deu-se início } \\
\text { para a realização no período de março a } \\
\text { novembro de } 2019 \text {, com caráter descritivo. } \\
\text { Foram analisadas referências do período } \\
\text { compreendido entre os anos de } 2000 \text { a } 2020 \text {. }\end{array}$ & $\begin{array}{l}\text { Os estudantes que apresentam autoestima baixa, períodos muito } \\
\text { prolongados de estudos e obrigações, alguns ainda conciliam } \\
\text { trabalho com estudos, apresentando fadiga e cansaço crônico, } \\
\text { cobranças familiares e sociais, afazem uso da automedicação com o } \\
\text { MTF, o mesmo proporciona uma máscara para que consigam } \\
\text { aguentar mais tempo e mais pressão constante }\end{array}$ \\
\hline
\end{tabular}


Research, Society and Development, v. 10, n. 10, e443101019108, 2021

(CC BY 4.0) | ISSN 2525-3409 | DOI: http://dx.doi.org/10.33448/rsd-v10i10.19108

\begin{tabular}{|c|c|c|c|c|c|}
\hline $\mathbf{N}^{\circ}$ & $\begin{array}{l}\text { AUTOR/ } \\
\text { ANO }\end{array}$ & $\begin{array}{c}\text { BANCO DE } \\
\text { DADO }\end{array}$ & OBJETIVO & METODOLOGIA & RESULTADOS \\
\hline 13 & $\begin{array}{c}\text { (Tolentino \& } \\
\text { Neto, 2019) }\end{array}$ & BVS & $\begin{array}{l}\text { Identificar a frequência de uso } \\
\text { do metilfenidato pelos } \\
\text { estudantes de medicina em } \\
\text { uma Faculdade de Medicina } \\
\text { em Brasília - Distrito Federal }\end{array}$ & $\begin{array}{l}\text { Estudo inquérito-transversal. Utilizou-se um } \\
\text { questionário fechado, aplicado aos alunos da } \\
1^{\text {a }} \text { a } 5^{\text {a }} \text { série do curso de Medicina. Os dados } \\
\text { foram tabulados e analisados no programa } \\
\text { IBM SPSS 20.0. Utilizou-se o nível de } \\
\text { significância } \alpha \leq 0,05 \text { e as variáveis nominais } \\
\text { comparadas através do teste Qui-quadrado }\end{array}$ & $\begin{array}{l}\text { Existe abuso do uso do metilfenidato entre os estudantes de } \\
\text { medicina desta faculdade com o objetivo de aperfeiçoar os } \\
\text { resultados acadêmicos. Mais da metade tem acesso ao } \\
\text { medicamento sem a prescrição médica. }\end{array}$ \\
\hline 14 & $\begin{array}{l}\text { (Nascimento et } \\
\text { al., 2019) }\end{array}$ & PubMed & $\begin{array}{l}\text { Avaliar a prática de } \\
\text { automedicação e as } \\
\text { particularidades atribuídas a } \\
\text { ela entre estudantes de } \\
\text { medicina de uma instituição } \\
\text { de ensino superior }\end{array}$ & $\begin{array}{l}\text { Trata-se de um estudo descritivo do tipo } \\
\text { transversal com abordagem quantitativa } \\
\text { realizado no Centro Universitário CESMAC } \\
\text { através de questionários aplicados aos } \\
\text { acadêmicos de medicina. }\end{array}$ & $\begin{array}{l}\text { A pesquisa ocorreu com } 280 \text { estudantes, desses, } 18 \% \text { afirmaram } \\
\text { saber onde comprar Ritalina sem receita. } 65,8 \% \text { acreditam que a } \\
\text { ritalina e muito usada em seu curso. Sobre quais as principais } \\
\text { influências que os levaram a realizar a automedicação, a resposta } \\
\text { mais prevalente foi o conhecimento próprio do indivíduo em } \\
67,1 \% \text {. fizeram recorrer à automedicação, os mais prevalentes } \\
\text { foram cefaleia em } 90 \% \text { dos casos }(252 / 280) \text {, gripe/resfriado em } \\
78,6 \%(220 / 280) \text {, febre em } 75,7 \%(212 / 280) \text {, outra dor em } 63,9 \% \\
(179 / 280) \text {, tosse em } 53,2 \%(149 / 280) \text {, infecções em } 31,8 \% \\
(89 / 280) \text { e, por fim, prevenção em } 14,3 \%(40 / 280) \text {. }\end{array}$ \\
\hline 15 & $\begin{array}{l}\text { (Candido et al., } \\
\text { 2020) }\end{array}$ & PubMed & $\begin{array}{l}\text { Estimar a prevalência e os } \\
\text { fatores associados ao uso de } \\
\text { metilfenidato para } \\
\text { Neuro-aprimoramento entre } \\
\text { estudantes universitários }\end{array}$ & $\begin{array}{l}\text { Amostra aleatória simples } \\
\text { de discentes da Universidade Federal de } \\
\text { Minas Gerais }(\mathrm{n}=438) \text {, convidados a } \\
\text { responder um } \\
\text { questionário online sobre o consumo de } \\
\text { metilfenidato. A coleta ocorreu de setembro } \\
\text { de } 2014 \text { a janeiro de } 2015 \text {. }\end{array}$ & $\begin{array}{l}\text { Dos } 378 \text { alunos incluídos, } 5,8 \%(\mathrm{n}=22) \text { declararam ter } \\
\text { feito uso de metilfenidato para neuro-aprimoramento, sendo } 41 \% \\
(9 / 22) \text { nas } 4 \text { semanas anteriores } \\
\text { a pesquisa. A situação da moradia foi a variável mais associada ao } \\
\text { uso de metilfenidato para neuro-aprimoramento. Relataram o uso } \\
\text { do metilfenidato para neuro-aprimoramento e outros fins nas } 4 \\
\text { semanas anteriores à pesquisa } 11 \text { estudantes, sendo que } 27 \% \text { não } \\
\text { apresentaram prescrição médica para adquiri-lo. }\end{array}$ \\
\hline 16 & $\begin{array}{c}\text { (Silva \& } \\
\text { Caldeiras, 2020) }\end{array}$ & PubMed & $\begin{array}{l}\text { Investigar a prevalência do } \\
\text { uso de psico-estimulantes } \\
\text { entre acadêmicos de uma } \\
\text { instituição } \\
\text { de ensino superior da região } \\
\text { da Zona da Mata de Minas } \\
\text { Gerais, avaliando as } \\
\text { motivações para o uso, } \\
\text { formas de consumo e }\end{array}$ & $\begin{array}{l}\text { Estudo descritivo, transversal realizado com } \\
\text { os estudantes matriculados nos cursos de } \\
\text { graduação em administração, ciências } \\
\text { contábeis, direito, enfermagem, farmácia, } \\
\text { fisioterapia e medicina de uma instituição } \\
\text { privada de ensino superior mineira através de } \\
\text { questionário que abordava questões } \\
\text { socioeconômicas e comportamentais sobre o } \\
\text { do uso dos psicoestimulantes. }\end{array}$ & $\begin{array}{l}\text { A prevalência de uso de psicoestimulantes na vida se deu } \\
\text { principalmente entre os estudantes de graduação dos cursos de } \\
\text { Medicina }(66,7 \%) \text { e Direito }(15,5 \%) \text {. Embora os usuários tenham } \\
\text { referido desconhecimento sobre o princípio ativo dos } \\
\text { psicoestimulantes que utilizavam, o metilfenidato foi a substância } \\
\text { predominante. }\end{array}$ \\
\hline
\end{tabular}


Research, Society and Development, v. 10, n. 10, e443101019108, 2021

(CC BY 4.0) | ISSN 2525-3409 | DOI: http://dx.doi.org/10.33448/rsd-v10i10.19108

\begin{tabular}{|c|c|c|c|c|c|}
\hline $\mathbf{N}^{\circ}$ & $\begin{array}{l}\text { AUTOR/ } \\
\text { ANO }\end{array}$ & $\begin{array}{l}\text { BANCO DE } \\
\text { DADO }\end{array}$ & OBJETIVO & METODOLOGIA & RESULTADOS \\
\hline & & & $\begin{array}{l}\text { aquisição e os efeitos sentidos } \\
\text { pós consumo. }\end{array}$ & & \\
\hline 17 & $\begin{array}{l}\text { (Rocha et al., } \\
\text { 2013) }\end{array}$ & BVS & $\begin{array}{l}\text { Investigar o uso do } \\
\text { medicamento metilfenidato } \\
\text { por acadêmicos do curso de } \\
\text { medicina do Centro } \\
\text { Universitário de Anápolis - } \\
\text { UniEVANGÉLICA, do } \\
\text { primeiro ao oitavo } \\
\text { período. }\end{array}$ & $\begin{array}{l}\text { O estudo é do tipo descritivo e transversal, o } \\
\text { estudo foi construído por meio de uma } \\
\text { amostra de conveniência com todos os } \\
\text { estudantes de medicina, com } 18 \text { anos de idade } \\
\text { ou mais, do primeiro }\left(1^{\circ}\right) \text { ao oitavo }\left(8^{\circ}\right) \\
\text { períodos que concordarem em participar da } \\
\text { pesquisa. Dessa forma, não houve a } \\
\text { necessidade de cálculo amostral. } 532 \text { pessoas } \\
\text { participaram da pesquisa. A coleta dos dados } \\
\text { ocorreu entre setembro de } 2019 \text { e dezembro } \\
\text { de } 2019 .\end{array}$ & $\begin{array}{c}\text { Dos que utilizaram o medicamento sem prescrição } 92 \text { relataram } \\
\text { que houve aumento do poder de concentração após o uso e } 55 \\
\text { apresentaram efeitos adversos. Pode-se perceber que a maioria dos } \\
\text { acadêmicos entrevistados já conhecem o metilfenidato, mesmo em } \\
\text { períodos mais iniciais do curso, porém o uso foi mais proeminente } \\
\text { sem prescrição médica, o que é preocupante, já que não existem } \\
\text { estudos que abordem como o medicamento age em pessoas sem } \\
\text { TDAH. }\end{array}$ \\
\hline 18 & $\begin{array}{l}\text { (Melo \& Souza, } \\
\text { 2020) }\end{array}$ & BVS & $\begin{array}{l}\text { Avaliar o uso do } \\
\text { metilfenidato para o } \\
\text { aprimoramento cognitivo } \\
\text { entre estudantes de Psicologia } \\
\text { da Universidade do Estado de } \\
\text { Minas Gerais }\end{array}$ & $\begin{array}{l}\text { Estudo epidemiológico, transversal, } \\
\text { quantitativo. A amostra foi composta por } \\
\text { discentes devidamente matriculados no } \\
\text { segundo semestre de } 2017(\mathrm{~N}=318) \text {. }\end{array}$ & $\begin{array}{l}\text { A maioria dos participantes era mulher ( } 80,8 \%) \text {, com idade entre } \\
18 \text { e } 63 \text { anos (média de } 26,5 \text { anos). Vinte e seis estudantes }(8,5 \%) \\
\text { declararam já ter usado metilfenidato em algum momento na vida, } \\
\text { doze declararam ter consumido o medicamento para fins de } \\
\text { aprimoramento cognitivo, sendo que, destes, sete obtiveram através } \\
\text { de amigos e nove começaram a usá-lo após o ingresso no ensino } \\
\text { superior. }\end{array}$ \\
\hline 19 & $\begin{array}{l}\text { (Bernardes et al., } \\
\text { 2020) }\end{array}$ & PubMed & $\begin{array}{l}\text { Estabelecer a porcentagem de } \\
\text { acadêmicos de medicina da } \\
\text { Universidade Federal de Jataí } \\
\text { que já realizaram a compra de } \\
\text { medicamentos sem orientação } \\
\text { qualificada }\end{array}$ & $\begin{array}{l}\text { Trata-se de um estudo descritivo e transversal } \\
\text { realizado por meio de um questionário } \\
\text { respondido pelos discentes do curso de } \\
\text { medicina no mês de novembro de } 2019 \text {. }\end{array}$ & $\begin{array}{c}\text { Mais de } 90 \% \text { dos discentes já compraram medicamentos sem } \\
\text { orientação qualificada. }\end{array}$ \\
\hline 20 & $\begin{array}{c}\text { (Miranda \& } \\
\text { Barbosa, 2021) }\end{array}$ & PubMed & $\begin{array}{l}\text { Avaliar a prevalência e } \\
\text { contextos académicos da } \\
\text { utilização de potenciadores } \\
\text { cognitivos numa amostra de } \\
\text { estudantes de medicina } \\
\text { portugueses }\end{array}$ & $\begin{array}{l}\text { Um questionário online sobre o uso de } \\
\text { potenciadores cognitivos foi respondido por } \\
1156 \text { participantes, que eram estudantes de } \\
\text { medicina (grupo 1) ou médicos recém- } \\
\text { formados que se candidatavam ao exame de } \\
\text { licenciamento médico português (grupo 2). }\end{array}$ & $\begin{array}{l}\text { Metilfenidato ( } 35 \%) \text { e modafinil ( } 10 \%) \text { foram as substâncias } \\
\text { prescritas mais consumidas e foram usados principalmente para } \\
\text { melhorar a atenção }(83 \%) \text { e a memória }(44 \%) \text {. }\end{array}$ \\
\hline
\end{tabular}


Research, Society and Development, v. 10, n. 10, e443101019108, 2021

(CC BY 4.0) | ISSN 2525-3409 | DOI: http://dx.doi.org/10.33448/rsd-v10i10.19108

\begin{tabular}{|c|c|c|c|c|c|}
\hline $\mathbf{N}^{\mathbf{o}}$ & $\begin{array}{l}\text { AUTOR/ } \\
\text { ANO }\end{array}$ & $\begin{array}{c}\text { BANCO DE } \\
\text { DADO }\end{array}$ & OBJETIVO & METODOLOGIA & RESULTADOS \\
\hline 21 & $\begin{array}{c}\text { (Carneiro, Gomes } \\
\& \text { Borges, 2021) }\end{array}$ & BVS & $\begin{array}{c}\text { Observar o perfil de uso de } \\
\text { metilfenidato e correlatos } \\
\text { (MFC) entre estudantes de } \\
\text { medicina e avaliar variáveis } \\
\text { relacionadas a qualidade do } \\
\text { sono e prática de atividade } \\
\text { física. }\end{array}$ & $\begin{array}{l}\text { Foi realizado um estudo transversal com } 180 \\
\text { estudantes de medicina via formulário online } \\
\text { em maio de } 2020 \text {. }\end{array}$ & $\begin{array}{c}\text { Observou-se que } 57,1 \%(\mathrm{n}=24) \text { tiveram diagnóstico médico com } \\
\text { equivalente prescrição de algum dos fármacos, enquanto } 42,9 \% \\
(\mathrm{n}=18) \text { fizeram uso não prescrito. Os medicamentos comerciais } \\
\text { citados foram: Ritalina }{ }^{\circledR} \text {, Venvanse®, Concerta® e Adderal@. Os } \\
\text { principais efeitos adversos relatados foram insônia }(62,1 \%), \\
\text { taquicardia }(58,6 \%) \text {, ansiedade }(51,7 \%) \text {, alteração do apetite } \\
(51,7 \%) \text {, estresse }(41,4 \%) \text {, tremores }(41,4 \%) \text {, boca seca }(34,5 \%) \text { e } \\
\text { abstinência }(17,2 \%) .\end{array}$ \\
\hline
\end{tabular}

Fonte: Autores. 
Research, Society and Development, v. 10, n. 10, e443101019108, 2021

(CC BY 4.0) | ISSN 2525-3409 | DOI: http://dx.doi.org/10.33448/rsd-v10i10.19108

A partir da análise do Quadro 4, foi possível organizar os estudos de acordo com seu banco de dados, sua metodologia de pesquisa e seus objetivos. Apesar da PubMed apresentar a maior quantidade de publicações, mais da metade dos trabalhos dessa plataforma são de acesso restrito. Nesse sentido, é possível destacar que a maioria dos estudos, 47, 6\%, foram coletados a BVS, seguidos por 8 (38\%) da PubMed e 3 (14, 28\%) da SciELO (Figura 4).

Figura 4: Distribuição dos artigos por banco de dados.

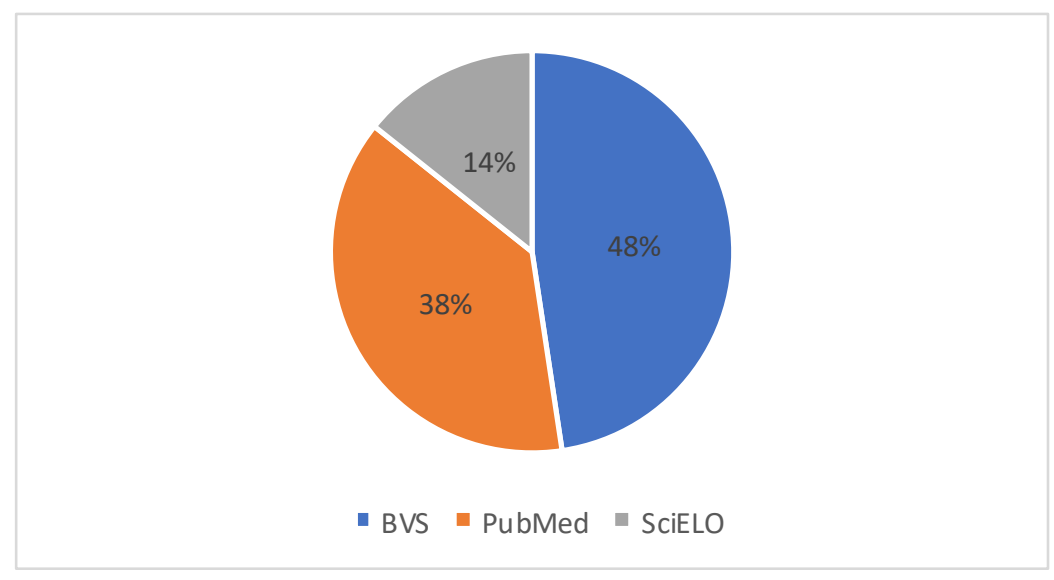

Fonte: Autores.

Em relação a metodologia, percebe-se que 90,4\% dos artigos apresentam uma modalidade de campo, com abordagem quantitativa. De acordo com (Tozoni-Reis, 2007), a pesquisa de campo consiste na busca de dados no próprio campo, ou seja, no espaço de pesquisa que contém a informação a ser investigada, é a ida do pesquisador ao campo de pesquisa para coletar dados a fim de compreender os fenômenos que ocorrem. Em relação a abordagem, o autor afirma que a pesquisa quantitativa são estudos em que os dados coletados da realidade estão em um formato numérico, com significados marcados pela expressão objetiva da análise dos próprios dados. A figura a seguir (Figura 5) demonstra a distribuição dos estudos em relação a sua metodologia de pesquisa.

Figura 5: Metodologia mais utilizada nos estudos.

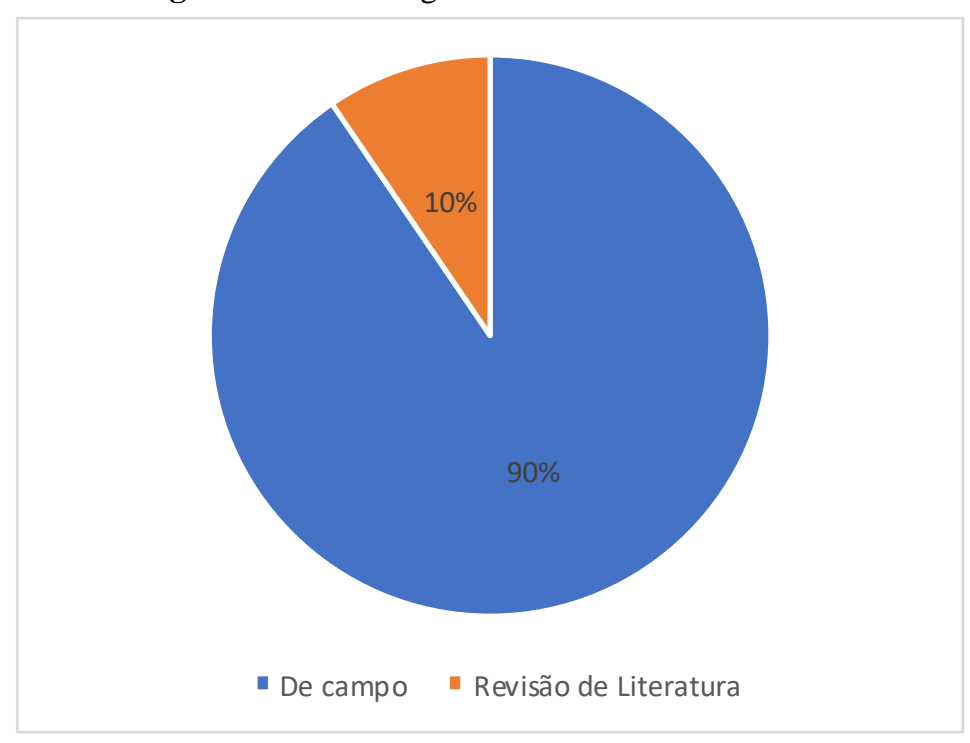

Fonte: Autores. 
Research, Society and Development, v. 10, n. 10, e443101019108, 2021

(CC BY 4.0) | ISSN 2525-3409 | DOI: http://dx.doi.org/10.33448/rsd-v10i10.19108

Em relação aos objetivos, 19 (90,47\%), dos 21 estudos, avaliaram a frequência do uso de metilfenidato por estudantes Universitários. Entre eles,11 trabalhos enfatizaram o uso desse medicamento no curso de medicina, 2 entre os alunos de psicologia, 4 artigos abordaram os cursos de farmácia e 2 questionaram universitários do curso de enfermagem.

As Figuras 6 e 7, representam a distribuição dos objetivos dos artigos selecionados em relação foco da sua investigação e sua população de estudos, respectivamente. A Figura 6 demonstra o foco de investigação dos estudos, desse modo é possível perceber uma grande preocupação voltada aos estudantes universitários.

Figura 6: Foco da investigação dos estudos.

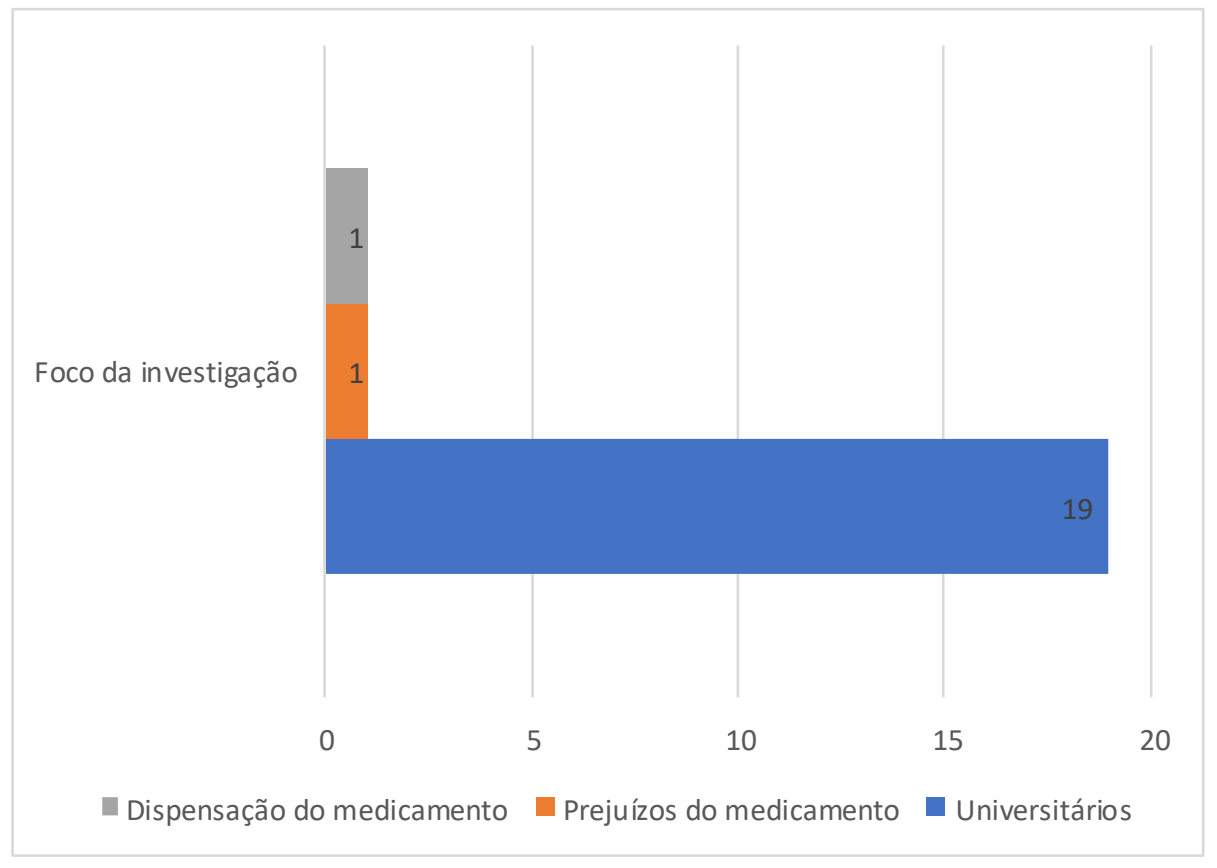

Fonte: Autores.

Figura 7: População estudada.

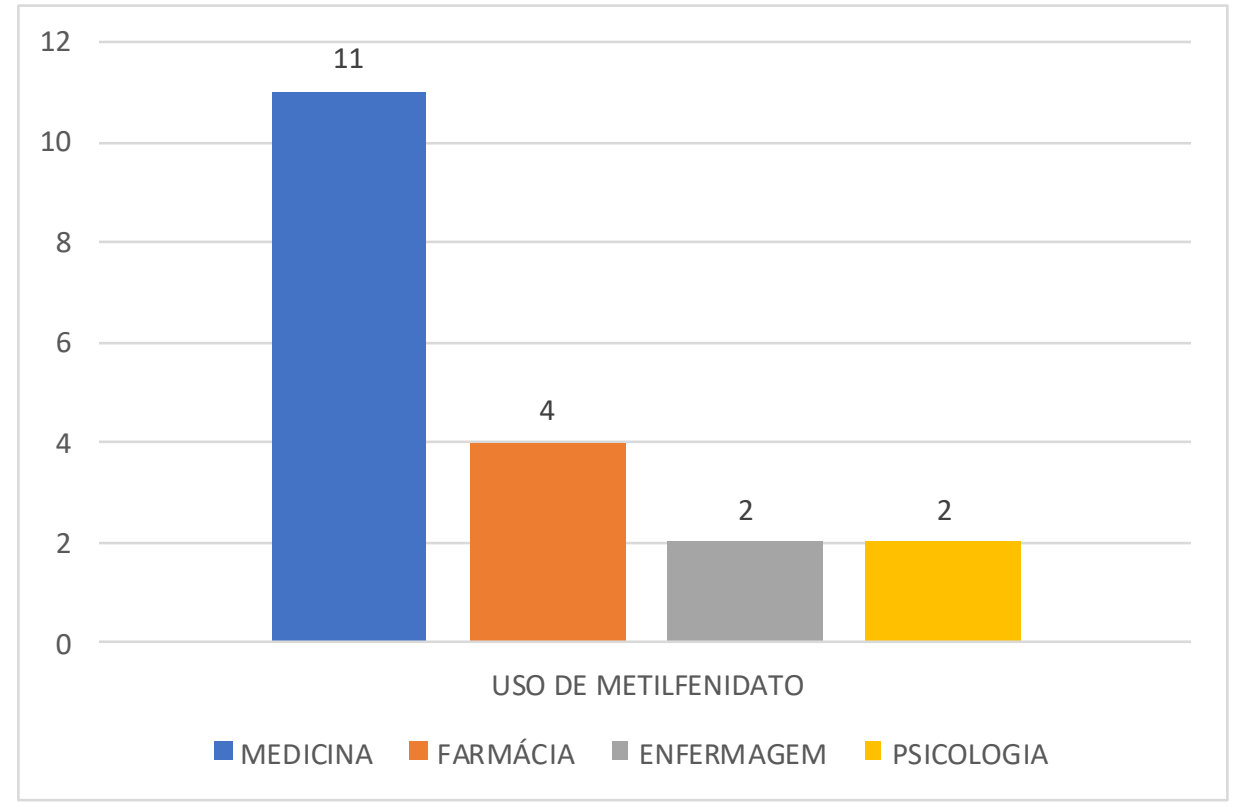

Fonte: Autores. 
É possível perceber que os estudantes do curso de medicina são os alunos que mais fazem uso de metilfenidato, seguidos pelos estudantes de farmácia, enfermagem e psicologia. Através dessa interpretação, nota-se que os estudantes que, ao longo de suas graduações, são instruídos sobre o uso e ação de medicamentos, são os que mais utilizam a Ritalina. Além dos dados apresentados, os 21 artigos possibilitaram abordar os assuntos definidos como eixo temáticos destes estudos. Como já mencionado na metodologia, esses eixos visam responder os objetivos propostos neste estudo.

\subsection{Explanação dos Eixos Temáticos}

\subsubsection{Indicações terapêuticas do metilfenidato e as consequências do uso prolongado}

Entre os estudo selecionados, 7 abordaram o eixo em questão. Para Girotto, Costa e Borges (2011) o metilfenidato é aprovado para o tratamento do transtorno de déficit de atenção e hiperatividade (TDAH) em crianças e adultos e como tratamento de segunda linha para narcolepsia em adultos. Crianças com diagnóstico de TDAH devem ter pelo menos seis anos de idade ou mais antes de começarem a tomar este medicamento. O tratamento tanto do TDAH quanto da narcolepsia tem resultados significativamente melhores quando usados simultaneamente com terapias não farmacológicas, isto é, treinamento de habilidades sociais no TDAH ou medidas de higiene do sono na narcolepsia (Silveira et al., 2014).

Os usos off label do metilfenidato incluem o tratamento da fadiga em pacientes com câncer, depressão refratária na população geriátrica, apatia na doença de Alzheimer e para melhorar o desempenho cognitivo. Uma vez que tem o potencial de ser abusado como um potenciador cognitivo, é um medicamento que carece de controle da ANVISA. A eficácia do metilfenidato para seus usos off label varia de limitada a moderada. A maioria desses usos relativamente novos ainda está sendo estudada e implementada na prática clínica (Burgard et al., 2013; Cohen et al., 2015).

As dosagens terapêuticas para TDAH ou narcolepsia prescritas pelos médicos não são prejudiciais o suficiente para ativar o sistema de recompensa do SNC, conhecido como núcleo accumbens. No entanto, dosagens excessivamente maiores tomadas por aqueles que abusam intencionalmente da droga levam a uma superexpressão de deltaFosB, um ativador da transcrição, em certos neurônios dentro do estriado (Roshini et al., 2017).

Ressalta-se que o tratamento de longo prazo com MPH tem efeitos neuropsiquiátricos adversos, seja durante ou após o tratamento prolongado, é, portanto, não apenas clinicamente importante, mas particularmente desafiador de responder. Por exemplo, a gravidade do TDAH pode ser um fator de confusão potencial importante, pois pode estar associada à necessidade de terapia com MPH de longo prazo e a altos níveis de comorbidade neuropsiquiátrica subjacente (Melo \& Souza, 2020).

Silva e Caldeiras (2020) afirmam que o problema de desemaranhar os riscos elevados de resultados adversos decorrentes do próprio TDAH ou dos riscos representados pela exposição aos medicamentos usados para tratá-lo pode ser abordado de uma variedade de maneiras e em muitas unidades de análise, desde estudos de caso longitudinais individuais até em âmbito nacional estudos de coorte. Cada abordagem pode contribuir com informações relevantes.

\subsubsection{Evidências do uso do metilfenidato sem indicação terapêutica, por estudantes, motivos e consequências}

As implicações e causas do uso de metilfenidato por estudantes foi amplamente discutida em 19 dos 21 estudos selecionados. De acordo com essas pesquisas, o motivo principal que leva o estudante a utilizar esse tipo de medicamento é o desejo por melhorar seu desempenho acadêmico.

Morgan et al. (2017), descobriram em seus estudos que os principais motivos alegados para o consumo de metilfenidato foram: reduzir o sono e melhorar raciocínio, atenção e/ou memória. Nessa mesma linha, Rocha et al. (2013), aplicaram um questionário a 532 estudantes universitários, entre eles, $87 \%$ relataram que, após fazer uso do medicamento em questão, perceberam aumento do seu poder de concentração. Alberto et al. (2017), aplicaram um questionaria aos acadêmicos 
de enfermagem, farmácia e biomedicina. Quando indagados sobre o motivo do uso 85\% declararam o ter realizado para melhorar o aprendizado. Desses, a metade foi do curso de Farmácia. Sendo que, 10\% utilizaram como proponente e apenas 5\% para tratamento do déficit de atenção. As conclusões dos estudos de Roshini et al. (2017), corroboram os autores supracitados, visto que o estudou comprovou que mais de $60 \%$ dos alunos que utilizam a Ritalina para melhorar seu aprendizado e tempo de estudo, fazem uso desse medicamento apenas durante os meses de aula. No período de férias, os estudantes suspendem esse consumo. Candido et al. (2020), apresentaram resultados similares aos estudos de Roshini et al. (2017), o consumo continuo de metilfenidato foi relatado apenas por 9,8\% da amostra abordada nessa pesquisa. Em contra partida, $41 \%$ dos estudantes entrevistados usavam o medicamento do início ao fim dos semestres e 49,2\% dos universitários utilizavam apenas durante o período de provas.

A flexibilidade e o motivo da utilização do metilfenidato, permite suspeitar que esses medicamentos são administrados sem acompanhamento profissional e adquiridos sem receita. Tolentino e Neto (2019), apresentaram em sua pesquisa que entre os alunos que fazem o uso da substância em foco, a maioria $(63,8 \%)$ não possui prescrição médica para tal consumo. Dentre os que apresentam receita médica, $71,43 \%$ declarou que são francos com os médicos e admitem que gostariam de usufruir do medicamento para poder melhorar a qualidade dos estudos.

No que se refere a forma de obtenção do fármaco, a maioria dos participantes do estudo de Melo e Souza (2020), declarou ter conseguido a substância através de amigos, além de terem iniciado o uso após a entrada na universidade. De acordo com Silveira et al. (2014), estudantes que iniciaram o uso após o ingresso em uma universidade justificaram tal prática devido ao estresse e às exigências vivenciadas no âmbito acadêmico (Silveira et al., 2014; Nascimento et al., 2019).

Bernardes et al., (2020), realizaram um estudo com 132 discentes, desses $90 \%$ afirmaram conseguir metilfenidato sem prescrição médica. A porcentagem de discentes que se sentem mais aptos à automedicação por estudarem da área da saúde aumenta à medida que o curso avança. Nesse sentido, o uso do conhecimento adquirido no meio acadêmico para a automedicação, tende a ser elevada em mais da metade entre os alunos que já ultrapassaram o quarto semestre de seus cursos (Roedel, Margarina \& Paim, 2017; Miranda \& Barbosa, 2021).

Nos estudos de Carneiro, Gomes e Borges (2021), foram apresentados resultados favoráveis ao uso de metilfenidato sob prescrição. Os autores demonstraram que, 57,1\% alegaram apresentar diagnóstico médico com equivalente prescrição para esse fármaco, enquanto os demais fazem uso não prescrito. Da parcela sob uso prescrito, os diagnósticos médicos apontados foram transtorno de déficit de atenção $(79,2 \%, \mathrm{n}=19)$, hiperatividade $(12,5 \%, \mathrm{n}=3)$ e narcolepsia $(8,3 \%$, $\mathrm{n}=2)$. No que se refere as consequências desse uso, pelos estudantes, os efeitos mais comuns apresentados nos estudos, foram dor abdominal, náusea, vômito, cefaleia, insônia, xerostomia, anorexia, taquicardia, palpitação, arritmias, alterações na pressão arterial, tosse, tiques, podem ser observados. Insônia e diminuição de apetite são diretamente proporcionais à dose do medicamento (Burgard et al., 2013; Eslami et al., 2014; Moura, 2017; Abbasi-Ghahramanloo et al., 2018; Deganutti, 2019).

\subsubsection{Impacto da atenção farmacêutica no uso racional de metilfenidato}

O metilfenidato é uma droga usualmente indicada para o tratamento de Transtorno do déficit de atenção com hiperatividade (TDAH), nesse sentido, o uso racional desse medicamento implica em utiliza-lo unicamente para conter transtornos psiquiátricos, o seu consumo para outros fins é considerado inadequado (Deganutti, 2019; Nascimento et al., 2019; Tolentino \& Neto, 2019).

O cloridrato de metilfenidato é um medicamento estimulante do SNC, pertence à classe das anfetaminas, uma substância psicotrópica (entorpecente) de controle internacional de prescrição de notificação obrigatória - A3, emitida na forma 
de cor amarela. A cor amarela indica a substância entorpecente como "uma substância que pode resultar em dependência física ou psicológica" (Bernardes et al., 2020; Carneiro, Gomes \& Borges, 2021; Miranda \& Barbosa, 2021).

Sabe-se que o farmacêutico é fundamental no tratamento de qualquer enfermidade, pois sua função é fornecer suporte ao paciente, à comunidade e à família, de forma a garantir a melhor qualidade de vida e um tratamento correto e eficaz. Tendo o dever de orientar os pacientes sobre a importância da adesão ao tratamento, esclarecendo sobre o uso correto da medicação, dosagem, como agir e seus efeitos colaterais e interações medicamentosas (Roshini et al., 2017; Abbasi-Ghahramanloo et al., 2018; Candido et al., 2020; Silva e Caldeiras, 2020).

O farmacêutico atua ainda ressaltando a importância do uso racional de medicamentos, auxiliando na prevenção do uso indevido de medicamentos usados no tratamento do TDAH, medicamentos que são estimulantes, muitas vezes utilizados indevidamente por alunos que buscam melhor desempenho em suas atividades escolares e acadêmicas. Frisa-se que a associação desse medicamento com o álcool pode potencializar os efeitos adversos no SNC e ocasionar sintomas como: arritmia cardíaca, crises de ansiedade, tensão e agitação. Sendo assim, o farmacêutico tem o papel de busca uma interação com o paciente, voltado para a farmacoterapia lógica, com excelentes resultados - melhorando a qualidade de vida dos pacientes (Melo \& Souza, 2020; Rocha et al., 2013).

\section{Considerações Finais}

Através deste estudo foi possível perceber que o uso indiscriminado do cloridrato de metilfenidato tem sido realizado com frequência por muitas pessoas, principalmente por estudantes, podendo levar a complicações sérias e o aparecimento de efeitos adversos graves, principalmente eventos cardiovasculares como taquicardia e hipertensão, transtornos psiquiátricos como depressão, psicose e dependência química, bem como do sistema neurológico como discinesia, contrações musculares involuntárias e espasmos, entre outros. Essa prática não é recomendada porque é perigosa e pode causar sérios problemas ao usuário. O cloridrato de metilfenidato deve ser prescrito pelo médico, somente com notificação de receita (lista A3 amarela). $\mathrm{O}$ aumento do uso indiscriminado do metilfenidato está associado a efeito imediato como estimulante do SNC, mas o que a maioria das pessoas desconhece são os efeitos adversos causados por esse medicamento. O farmacêutico como profissional de saúde deve orientar os usuários do metilfenidato e esclarecer a população quanto ao uso abusivo dessa droga, e garantir o cumprimento das normas sanitárias relacionadas ao uso deste medicamento. Assim, podemos concluir que estudos futuros é um grande ponto de partida para se investigar seus efeitos adversos, e assim, poder auxiliar na prevenção no uso indevido de medicamento.

\section{Referências}

Abbasi-Ghahramanloo, A., Khodadost, M., Moradpour, F., Karimirad, M. R., Kamali, R., \& Ziarati, F. (2018). Prevalence of nonmedical use of prescriptiontype opioids, methylphenidate, and sedative-hypnotics among university students in the south of Iran: a regression analysis. Electronic physician, 10(6), 69816987. https://doi.org/10.19082/6981

Alberto, M. S. I., Valiatti, T. B., Barcelos, I. B., \& Salvi, J. O. (2017). Uso de metilfenidato entre acadêmicos no interior de Rondônia. Revista da Universidade Vale do Rio Verde, 15(1), 170-178.

ANVISA. Agência Nacional de Vigilância Sanitária. Portaria no 344, de 12 de maio de 1998. (1998). Aprova o Regulamento Técnico sobre substâncias e medicamentos sujeitos a controle especial [Approves the Technical Regulation on substances and medicinal products subject to special control]. 1998. http://bvsms.saude.gov.br/bvs/saudelegis/svs/1998/prt0344_12_05_1998_rep.html

ANVISA. RDC N 27, de 30 de março de 2007. (2007). Dispõe sobre o Sistema Nacional de Gerenciamento de Produtos Controlados - SNGPC e estabelece a implantação do módulo para drogarias e farmácias e dá outras providências.

ANVISA. Resolução Normativa - RN No 424, de 26 de junho de 2017. (2017). Dispõe sobre critérios para a realização de junta médica ou odontológica formada para dirimir divergência técnico-assistencial sobre procedimento ou evento em saúde a ser coberto pelas operadoras de planos de assistência à saúde. 
Research, Society and Development, v. 10, n. 10, e443101019108, 2021 (CC BY 4.0) | ISSN 2525-3409 | DOI: http://dx.doi.org/10.33448/rsd-v10i10.19108

Bardin, L. (1977). L'analyse de contenu. Presses universitaires de France.

Bernardes, H. C., Costa, F. F., Wanderley, J. C. S. Farias, J. P., Liberato, L. S., \& Villela, E. F. M. (2020). Epidemiological profile of self-medication among medical academics of a brazilian public university. Brazilian Journal of Health Review, 3(4), 8631-8643.

Burgard, D. A., Fuller, R., Becker, B., Ferrell, R., \& Dinglasan-Panlilio, M. J. (2013). Potential trends in Attention Deficit Hyperactivity Disorder (ADHD) drug use on a college campus: wastewater analysis of amphetamine and ritalinic acid. The Science of the total environment, $450-451$, 242-249. https://doi.org/10.1016/j.scitotenv.2013.02.020

Candido, R. C. F., Perini, E., Pádua, C. M., \& Junqueira, D. R. (2020). Prevalence of and factors associated with the use of methylphenidate for cognitive enhancement among university students. Einstein (São Paulo), 18. https://doi.org/10.31744/einstein_journal/2020AO4745.

Carneiro, N. B. S., Gomes, D. A. S., \& Borges, L. L. (2021). Perfil de uso de metilfenidato e correlatos entre estudantes de medicina. Revista Eletrônica Acervo Saúde, 13(2).

Cohen, Y. G., Segev, R. W., Shlafman, N., Novack, V., \& Ifergane, G. (2015). Methylphenidate use among medical students at Ben-Gurion University of the Negev. Journal of neurosciences in rural practice, 6(3), 320-325. https://doi.org/10.4103/0976-3147.158749

Deganutti, D. (2019). Motivos que levam o estudante de ensino superior a fazerem a utilização do metilfenidado. 31 f. Trabalho de Conclusão de Curso (TCC). Apresentado ao curso de Farmácia da Faculdade de Educação e Meio Ambiente - FAEMA.

Eslami, A. A., Jalilian, F., Ataee, M., Alavijeh, M. M., Mahboubi, M., Afsar, A., \& Aghaei, A. (2014). Intention and willingness in understanding Ritalin misuse among Iranian medical college students: a cross-sectional study. Global journal of health science, 6(6), 43-53. https://doi.org/10.5539/gjhs.v6n6p43

Galvão, C. M., Sawada, N. O., \& Mendes, I. A. C. (2003). A busca das melhores evidências. Revista da Escola de Enfermagem da USP, 37(4,), 43-50.

Ganong L. H. (1987). Integrative reviews of nursing research. Research in nursing \& health, 10(1), 1-11.

Girotto, E., Costa, C. K., \& Borges, L. da S. (2011). Caracterização das prescrições de metilfenidato em rede de farmácias do município de londrina, Paraná, 2010. Revista Eletrônica De Farmácia, 8(3), 15. https://doi.org/10.5216/ref.v8i3.15801

Masini, L. D., Dantas, L. W.P., \& Nunes, L. O. (2019). Análise do consumo de estimulantes cerebrais por estudantes de medicina de uma faculdade do oeste da Bahia. IN: $17^{\circ}$ Congresso de Iniciação Científica da FASB.

Melo, T. M., \& de Souza, R. S. B. (2020). 'Ṕ́lula do estudo': uso do metilfenidato para aprimoramento cognitivo entre estudantes de psicologia da Universidade do Estado de Minas Gerais (UEMG). Revista Ciências Em Saúde, 10(2), 56-62. https://doi.org/10.21876/rcshci.v10i2.887

Miranda, M., \& Barbosa, M. (2021). Estratégias de Aprimoramento Cognitivo em Estudantes de Medicina Portugueses: Qual a Relevância dos Desafios académicos? Revista Científica da Ordem dos Médicos.

Morgan, H. L., Petry, A. F., Licks, P. A. K., Ballester, A. O., Teixeira, K. N., \& Dumith, S. C. (2017). Consumo de Estimulantes Cerebrais por Estudantes de Medicina de uma Universidade do Extremo Sul do Brasil: Prevalência, Motivação e Efeitos Percebidos. Revista Brasileira de Educação Médica, 41(1), 102109.

Nascimento, C. S. do., Araújo, K. M. M. de., Gusmão, D. B. M. de., Souza, P. M., \& Santos Júnior, J. A. dos. (2019). Avaliação da automedicação entre estudantes de medicina de uma instituição de ensino de Alagoas. Revista De Medicina, 98(6), 367-373. https://doi.org/10.11606/issn.1679-9836.v98i6p367373

Ortega, F., Barros, D., Caliman, L., Itaborahy, C., Junqueira, L., Ferreira, C. P. (2010). Ritalin in Brazil: production, discourse and practices. Interface Comunicação, Saúde, Educação, 14(34), 499-512. Disponível em: <https://doi.org/10.1590/S1414-32832010005000003>. https://doi.org/10.1590/S141432832010005000003 .

Rocha, B.S., \& Werlang, M.C. (2013). Psychotropic drugs in Family Health Strategy: profile of use, access and strategies to promote the rational use. Ciência \& Saúde Coletiva, 18(11), 3291-3300. http://www.cienciaesaudecoletiva.com.br/artigos/psicofarmacos-na-estrategia-saude-da-familia-perfil-de-utilizacaoacesso-e-estrategias-para-a-promocao-do-uso-racional/10761?id=10761

Roedel, A. M., Margarina, F. X., \& Paim, R. S. P. (2017). Uso de metilfenidato entre estudantes de psicologia de uma instituição de ensino superior da Serra Gaúcha. In: V Congresso de Pesquisa e Extensão da FSG III Salão de Extensão.

Roshini, J., Chang, C. C., Koto, M., Geldenhuys, A., Nichol, A., \& Joubert, G. (2017). Non-medical use of methylphenidate among medical students of the University of the Free State. South African Journal of Psychiatry, 23(1), 1-5. https://dx.doi.org/10.4102/sajpsychiatry.v23.1006

Silva, F. C. da., Moreno, F. C. de B., Bender, P. F. M., \& Carvalho, C. D. B. de. (2008). Prevenção da Dor Fantasma com Uso de Cloridrato de Amitriptilina. Revista Brasileira De Cancerologia, 54(4), 345-349. https://doi.org/10.32635/2176-9745.RBC.2008v54n4.1688

Silveira, R. R., Lejderman, B., Ferreira, P. E. M. S., \& Rocha, G. M. P. (2014). Patterns of non-medical use of methylphenidate among 5th and 6th year students in a medical school in Southern Brazil. Trends Psychiatry Psychother,36(2), 101-106.

Tolentino, J. E. F., \& Netto, J. P. S. (2019). O uso off label de metilfenidato entre estudantes de medicina para aprimoramento do desempenho acadêmico, Comunicação em Ciências da Saúde, 30(1):39-44

Winterstein, A. G., Gerhard, T., Kubilis, P., Saidi, A., Linden, S., Crystal, S., Zito, J., Shuster, J. J. (2012). Cardiovascular safety of central nervous system stimulants in children and adolescents: population based cohort study. British Medical Journal (Clinical Research Edition), 3(5), 345-e4627. doi: https://doi.org/10.1136/bmj.e4627 